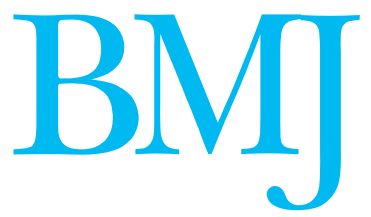

\title{
Health and health care in transitional Europe
}

\author{
Evidence based policy making and greater public participation are needed
}

I

n December 2004 we called for papers that would document the impact on population health and on health systems of the transition from communism in Europe and central Asia. ${ }^{\mathrm{w} 1}$ Over the past 18 months, a series of events has focused the eyes of the world on this region. May 2004 saw the historic enlargement of the European Union. In Georgia, Ukraine, and Kyrgyzstan, popular uprisings have led to the removal of autocratic regimes; in Uzbekistan, a similar uprising ended in tragedy. Yet, despite coming to the attention of the world's mass media, this vast region characterised by diversity and shared problems has generated surprisingly few publications on health and health care. We hope that this theme issue-most of it contributed by researchers and authors from the region-will fill some of these gaps and will further stimulate much needed monitoring, research, and debate.

One of the key themes in this week's BMJ theme issue is the rising prevalence of HIV/AIDS in some countries of the region. For example, one paper focuses on Ukraine, which has the highest prevalence of HIV infection in Europe (estimated at 1.4\% of the population) but lacks any systematic approach to prevention, treatment, or care. ${ }^{1}$ The authors report how information on the scale and nature of the problem is patchy and is not well known within Ukraine. An accompanying commentary emphasises the need for urgent international action to prevent a potential

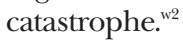

Non-communicable diseases continue to dominate the overall burden of disease in the region. ${ }^{2}$ Yet some countries have seen marked reductions in mortality, ${ }^{3}$ and, although precise explanations for this remain a matter for discussion, ${ }^{\mathrm{w} 3}$ it is clear that much can be done to tackle the high toll from cardiovascular disease. As Marquez and Suhrcke note, however, continuing improvement will depend on much more evidence and better use of existing evidence ${ }^{45}$ to inform policy, as well as on the creation of systems to collect data regularly on risk factors for chronic disease.

\section{Low on the policy agenda}

As is so often the case elsewhere, mental health remains low on the policy agenda. There is a great deal to do to overcome the legacy of psychiatry under communist rule. An editorial in this issue draws attention to some of the most pressing issues facing those struggling to care for people with mental disorders in cal data about the scale of the problem, implementation of evidence based interventions, and collaborative intersectoral work to deliver appropriate care. They also argue for comprehensive policies on mental health that are based on accurate assessments of societal context, populations' needs, and availability of existing services-warning of the dangers that lie ahead if such reforms are inadequately planned and resourced.

Across this region, health systems have undergone extensive and varied reforms. ${ }^{7}$ But there is still much to do, particularly in strengthening primary care, which in many places has yet to develop effective prevention and gatekeeping. ${ }^{8}$ Creating a cadre of modern primary care doctors has been a daunting task, facing many obstacles such as inconsistent legislation and weak policy frameworks. An encouraging sign is that, despite limited resources, only a few of the newly trained family doctors have chosen to join the private sector-only $2 \%$ in Kosovo and $6 \%$ in Russia. Difficulties do not end with completion of retraining, however: many deep rooted cultural and behavioural problems still need to be overcome before primary care can really succeed in the region. ${ }^{10}$

One important and deep rooted problemreported in several papers this week-is corruption, which is undermining efforts to improve health and health care in many parts of the region. Healthcare structures are often too bureaucratic and are designed to satisfy the requirements of potential foreign partners rather than to benefit patients or adhere to adequate moral and ethical standards. ${ }^{11}$ The lack of a moral framework further complicates the already difficult circumstances in which healthcare reforms take place as, for example, in Hungary. ${ }^{12}$

Political transition has yielded mixed fortunes. In too many countries the population remains excluded from the political process. Where democracy has taken root in this region, health has improved, ${ }^{\mathrm{w} 4}$ although not yet to the levels seen in western Europe. Many citizens remain insufficiently involved in decisions about their health or the care they receive. ${ }^{13}$ To participate fully and effectively they need information, and we hope that this theme issue will provide some of it. They also need to realise that they can make a difference.

Obtaining democratic power has been a slow and painful process in the region. Using that power, its

Additional references w1-w4 are on bmj.com 
citizens should demand health care in line with the rest of Europe's.

\section{Kristina Fister Roger Robinson editorial registrar} BMJ (kfister@bmj.com)

Martin McKee professor of European public health European Centre, London School of Hygiene and Tropical Medicine, London WC1E 7HT

We thank Roza Adany and Vasily Vlassov for their helpful inputs at the initial stage of preparing this theme issue.

Competing interests: None declared.

DeBell D, Carter R. Impact of transition on public health in Ukraine: case study of the HIV/AIDS epidemic. BMJ 2005;331:216-9.

2 Marquez PV, Suhrcke M. Combating non-communicable diseases. BMJ 2005;331:174.

3 Zatonski WA, Willett W. Changes in dietary fat and declining coronary heart disease in Poland: population based study. BMJ 2005;331:187-8.
4 Kern J, Strnad M, Coric T, Vuletic S. Cardiovascular risk factors in Croatia: struggling to provide the evidence for developing policy recomCroatia: struggling to provide the evide
mendations. BMJ 2005:331:208-10.

5 Didkowska J, Manczuk M, McNeill A, Powles J, Zatonski W. Lung cancer mortality at ages 35-54 in the European Union: ecological study of evolving tobacco epidemics. BMJ 2005;331:189-91.

6 Jenkins R, Klein J, Parker C. Mental health in post-communist states. BMJ 2005;331:173-4.

7 Figueras J, Menabde N, Busse R. The road to freedom. BMJ 2005;331:170-1.

8 Hedley RN, Maxhuni B. Development of family medicine in Kosovo. BMJ 2005;331:201-3.

9 Rese A, Balabanova D, Danishevski K, McKee M, Sheaff R. Implementing general practice in Russia: getting beyond the first steps. BMJ 2005;331:204-7.

10 Burazeri G, Roshi E, Jewkes R, Jordan S, Bjegovic V, Laaser U. Factors associated with spousal physical violence in Albania: cross sectional study. BMJ 2005;331:197-201

11 Borovecki A, ten Have H, Oreskovic S. Ethics and the structures of health care in the European countries in transition: hospital ethics committees in Croatia. BMJ 2005;331:227-9.

12 Szocska MK, Réthelyi JM, Normand C. Managing healthcare reform in Hungary: challenges and opportunities. BMJ 2005;331:231-3.

13 Mastilica M, Kusec S. Croatian healthcare system in transition, from the perspective of users. BMJ 2005;331:223-6.

\title{
The road to reform
}

\author{
Look to the neighbours
}

$\mathrm{T}$ The political transition in central and eastern Europe has not spared the region's health systems. Almost everywhere governments have abandoned the Soviet model of health care. ${ }^{1}$ Initially, this model achieved much at first in ensuring universal access to health services and tackling common infectious diseases. Yet, by the 1970s, the cracks were appearing, and now many people in the region are dying from causes that should be preventable with timely and effective health care. ${ }^{2}$

Health systems in the region have had to respond to a variety of economic and political pressures as well as to the populations' longstanding healthcare problems. Many services were of low quality and were characterised by poorly motivated health professionals, poor responsiveness to citizens' needs, and outdated clinical practices. ${ }^{1}$

Although the range and depth of challenges has varied between countries, some are common to many of them. One of the greatest challenges has been the quest for sustainable financing. Most countries in the region were quick to reject the former model of financing from general government revenues, owing to general mistrust in governments and to the desire to follow what were perceived as superior models used in neighbouring countries. ${ }^{3}$ Some form of social health insurance, based on contributions from individuals according to their earnings, seemed to offer a solution. ${ }^{4}$

\section{Not so easy}

Implementing systems of social insurance for health care has proved, however, to be much more complex than expected. In countries with large informal economies, high unemployment, and severe macroeconomic constraints-many have not yet reached the levels of gross domestic product (GDP) they had before political transition-the revenue base has been very small. The high costs of social insurance have fallen on those in employment, increasing labour costs and further encouraging working informally without paying tax or insurance..$^{5}$ In many countries, governments have had to make large scale transfers into health care from general revenues, and in some the move towards social health insurance has been reversed.

The continuing shortage of funds in many of the countries in this region has encouraged the persistent and widespread use of informal or "under the table" payments. $^{5}$ This hampers equitable access to health care, ${ }^{6}$ creates many perverse incentives for doctors, and acts as a serious obstacle to implementing reform. ${ }^{7}$ There have been, however, some encouraging experiences with regulating or formalising these fees as co-payments into local funds used by doctors and hospitals to improve services. ${ }^{8}$ There have also been considerable improvements in purchasing practices, with some countries adopting effective contracting strategies and more than half moving from a system based on fee for service to performance related capitation in primary care and global budgets for hospital care. $^{9}$

But these incentives have been effective only in those countries that have brought in concomitant reform of healthcare provision. The model of care based on inadequately and narrowly trained doctors in primary care, whose main roles were controlling absence from work due to sickness and acting as signposts to an extensive but poorly equipped hospital sector, has become obsolete. A new and more effective model of primary care based on family practitioners is taking root in many countries, in particular in central Europe. A paper on Russia by Rese et al in this week's $B M J$ shows, ${ }^{10}$ however, that much remains to be done in some parts of the region.

In addition, several countries have restructured the hospital sector to reduce the oversupply of beds and increase efficiency. The number of beds remains much higher than that in western European 